\title{
Parametric studies of contrail ice particle formation in jet regime using microphysical parcel modeling
}

\author{
H.-W. Wong and R. C. Miake-Lye \\ Center for Aero-Thermodynamics, Aerodyne Research, Inc., Billerica, Massachusetts, USA \\ Received: 18 August 2009 - Published in Atmos. Chem. Phys. Discuss.: 22 October 2009 \\ Revised: 19 March 2010 - Accepted: 22 March 2010 - Published: 6 April 2010
}

\begin{abstract}
Condensation trails (contrails) formed from water vapor emissions behind aircraft engines are the most uncertain components of the aviation impacts on climate change. To gain improved knowledge of contrail and contrail-induced cirrus cloud formation, understanding of contrail ice particle formation immediately after aircraft engines is needed. Despite many efforts spent in modeling the microphysics of ice crystal formation in jet regime (with a plume age $<5 \mathrm{~s}$ ), systematic understanding of parametric effects of variables affecting contrail ice particle formation is still limited. In this work, we apply a microphysical parcel modeling approach to study contrail ice particle formation in nearfield aircraft plumes up to $1000 \mathrm{~m}$ downstream of an aircraft engine in the soot-rich regime (soot number emission index $\left.>1 \times 10^{15}(\mathrm{~kg} \text {-fuel })^{-1}\right)$ at cruise. The effects of dilution history, ion-mediated nucleation, ambient relative humidity, fuel sulfur contents, and initial soot emissions were investigated. Our simulation results suggest that ice particles are mainly formed by water condensation on emitted soot particles. The growth of ice coated soot particles is driven by water vapor emissions in the first $1000 \mathrm{~m}$ and by ambient relative humidity afterwards. The presence of chemi-ions does not significantly contribute to the formation of ice particles in the soot-rich regime, and the effect of fuel sulfur contents is small over the range typical of standard jet fuels. The initial properties of soot emissions play the most critical role, and our calculations suggest that higher number concentration and smaller size of contrail particle nuclei may be able to effectively suppress the formation of contrail ice particles. Further modeling and experimental studies are needed to verify if our findings can provide a possible approach for contrail mitigation.
\end{abstract}

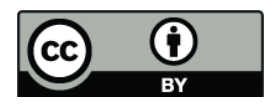

Correspondence to: H.-W. Wong (hwwong@aerodyne.com)

\section{Introduction}

Environmental concerns over aviation emissions on the current and projected climate change have increased as air traffic and aviation industry continue to grow (Wuebbles, 2006). Among aviation emissions, condensation trails (contrails) formed from water vapor emissions behind aircraft engines has gained greater attention during recent years. Contrails are formed under certain thermodynamic constraints (Schmidt, 1941; Appleman, 1953; Schumann, 2005) and can evolve into cirrus clouds under favorable conditions (Minnis et al., 2004). Both contrails and contrail-induced cirrus clouds could play important roles in the global climate change via affecting the radiation budget. The Intergovernmental Panel on Climate Change (IPCC) identified contrails as the most uncertain components of the aviation impacts on climate with a low level of scientific understanding (Sausen et al., 2005; Lee et al., 2009). Clearly, knowledge of how contrail ice particles are formed from aircraft emissions and how they evolve into contrails and cirrus clouds is critical to understanding climate impacts of contrails and contrailinduced cirrus clouds.

Many field measurements, such as Subsonic Aircraft: Contrail and Cloud Effects Special Study (SUCCESS) (Toon and Miake-Lye, 1998), Pollution from Aircraft Emissions in the North Atlantic Flight Corridor (POLINAT) (Schumann, 2000), and SULFUR series (Schumann et al., 2002), were carried out to elucidate important parameters affecting contrail ice particle formation and contrail evolution. Modeling studies were also performed to understand contrail formation mechanisms and potential impacts of contrails to global climate change (Brown et al., 1996; Kärcher, 1998a; Yu and Turco, 1998; Kärcher et al., 2007). The initial properties of ice crystals in near-field aircraft plumes are of particular interest, since these properties are critical in the representation of emitted aerosols and contrails in large scale models

Published by Copernicus Publications on behalf of the European Geosciences Union. 
such as global climate models or large eddy simulations (Shirgaonkar and Lele, 2006). This information can only be obtained via modeling due to instrumental limitations in near-field aircraft plumes within five wingspans downstream $(\sim 1 \mathrm{~s})$ of an aircraft engine.

Despite many efforts spent in modeling the microphysics of ice crystal formation in jet regime (with a plume age $<5 \mathrm{~s}$ ), systematic understanding of the roles of chemi-ions, ambient conditions, fuel sulfur contents, and soot emissions in the formation and evolution of contrail ice particles immediately after the engine-exit plane is still limited. In this work, we apply a microphysical parcel modeling approach to study the microphysics of ice particle formation in near-field aircraft plumes up to $1000 \mathrm{~m}$ downstream of an aircraft engine at cruise. The results from our microphysical calculations are presented.

\section{Microphysical model for ice particle formation}

We apply the microphysical parcel model we developed previously (Brown et al., 1996; Wong et al., 2008) to study ice particle formation in near-field aircraft plumes at cruise. Our model tracks time evolution of a gaseous or a particle species in a jet engine exhaust in terms of contributions of chemistry, plume dilution and mixing, and microphysical processes as (Kärcher, 1998a):

$\frac{d X_{i}}{d t}=\left.\frac{d X_{i}}{d t}\right|_{\text {chemistry }}+\left.\frac{d X_{i}}{d t}\right|_{\text {mixing }}+\left.\frac{d X_{i}}{d t}\right|_{\text {microphysics }}$

The contribution of chemistry comes from the chemical molar production rates of gaseous species. In our model, we use a gas-phase reaction mechanism consisting of 35 chemical species and 181 chemical reactions, which was derived from the $\mathrm{NO}_{\mathrm{x}}$ and $\mathrm{SO}_{\mathrm{x}}$ combustion mechanism by Muller et al. (2000) and the $\mathrm{H}_{2} \mathrm{SO}_{4}$ formation pathway reported in our previous study (Brown et al., 1996). The contribution of plume dilution and mixing is described as:

$$
\left.\frac{d X_{i}}{d t}\right|_{\text {mixing }}=\left(X_{i}-X_{\mathrm{amb}, i}\right) \cdot \frac{d f(t)}{d t} \cdot \frac{1}{f(t)}
$$

where $f(t)$ is the exhaust mass fraction which explains how the plume is diluted by the ambient air. In our model, $f(t)$ is evaluated using the simple dilution profile reported by Schumann et al. (1998), which was determined from measured plume properties behind aircraft at cruise altitudes for plume ages of seconds to hours.

The contribution of microphysical processes is further divided into contributions of homogeneous nucleation of new particles, coagulation among liquid particles, and activation and condensational growth on soot particles as:

$$
\begin{aligned}
& \left.\frac{d X_{i}}{d t}\right|_{\text {microphysics }}=\left.\frac{d X_{i}}{d t}\right|_{\text {nucleation }}+\left.\frac{d X_{i}}{d t}\right|_{\text {coagulation }} \\
& +\left.\frac{d X_{i}}{d t}\right|_{\text {soot }}
\end{aligned}
$$

Homogeneous nucleation of new particles is described by the kinetic quasi-unary nucleation (KQUN) theory developed by $\mathrm{Yu}(2005,2006 \mathrm{a}, 2007)$. In the cases where the role of chemiions may be important, the kinetic ion-mediated nucleation (IMN) model developed by $\mathrm{Yu}$ (2006b) is used. In both KQUN and IMN, binary nucleation of $\mathrm{H}_{2} \mathrm{SO}_{4}-\mathrm{H}_{2} \mathrm{O}$ is treated as unary nucleation of sulfuric acid, and the embryo formation rates due to homogeneous binary nucleation are derived explicitly from the condensation and evaporation rates as:

$$
\begin{aligned}
\frac{d n_{1}^{0}}{d t} & =\gamma_{2,0}^{0} n_{2}^{0}-\sum_{j=1}^{j_{\max }-1}\left(\beta_{j, 0}^{0} n_{j}^{0}+\beta_{j,+}^{+} n_{j}^{+}+\beta_{j,-}^{-} n_{j}^{-}\right) \\
& +\sum_{j=2}^{j_{\max }}\left(\gamma_{j, 0}^{0} n_{j}^{0}+\gamma_{j,+}^{+} n_{j}^{+}+\gamma_{j,-}^{-} n_{j}^{-}\right)
\end{aligned}
$$

(neutral, $i=1$ )

$$
\begin{aligned}
\frac{d n_{1}^{+}}{d t} & =-\sum_{j=1}^{j_{\max }-1}\left(\beta_{j,+}^{0} n_{j}^{0}+\beta_{j, 0}^{-} n_{j}^{-}\right) \\
& +\sum_{j=2}^{j_{\max }}\left(\gamma_{j, 0}^{+} n_{j}^{+}+\gamma_{j,-}^{0} n_{j}^{0}\right)
\end{aligned}
$$

(positive, $i=1$ )

$$
\begin{aligned}
\frac{d n_{1}^{-}}{d t} & =-\sum_{j=1}^{j_{\max }-1}\left(\beta_{j,-}^{0} n_{j}^{0}+\beta_{j, 0}^{+} n_{j}^{+}\right) \\
& +\sum_{j=2}^{j_{\max }}\left(\gamma_{j, 0}^{-} n_{j}^{-}+\gamma_{j,+}^{0} n_{j}^{0}\right)
\end{aligned}
$$

(negative, $i=1$ )

$$
\begin{aligned}
\frac{d n_{i}^{0}}{d t} & =\delta_{i}\left(\beta_{i-1,0}^{+} n_{i-1}^{+}+\beta_{i-1,0}^{-} n_{i-1}^{-}+\beta_{i-1,0}^{0} n_{i-1}^{0}\right) \\
& -\left(\gamma_{i,+}^{0}+\gamma_{i,-}^{0}+\gamma_{i, 0}^{0}\right) n_{i}^{0}-\left(\beta_{i,+}^{0}+\beta_{i,-}^{0}+\beta_{i, 0}^{0}\right) n_{i}^{0} \\
& +\left(\gamma_{i+1,0}^{+} n_{i+1}^{+}+\gamma_{i+1,0}^{-} n_{i+1}^{-}+\gamma_{i+1,0}^{0} n_{i+1}^{0}\right)
\end{aligned}
$$

(neutral, $i \geq 2$ )

$$
\begin{aligned}
\frac{d n_{i}^{+}}{d t} & =\delta_{i}\left(\beta_{i-1,+}^{+} n_{i-1}^{+}+\beta_{i-1,+}^{0} n_{i-1}^{0}\right)-\left(\gamma_{i,+}^{+}+\gamma_{i, 0}^{+}\right) n_{i}^{+} \\
& -\left(\beta_{i,+}^{+}+\beta_{i, 0}^{+}\right) n_{i}^{+}+\left(\gamma_{i+1,+}^{+} n_{i+1}^{+}+\gamma_{i+1,+}^{0} n_{i+1}^{0}\right)
\end{aligned}
$$

(positive, $i \geq 2$ )

$$
\begin{aligned}
\frac{d n_{i}^{-}}{d t} & =\delta_{i}\left(\beta_{i-1,-}^{-} n_{i-1}^{-}+\beta_{i-1,-}^{0} n_{i-1}^{0}\right)-\left(\gamma_{i,-}^{-}+\gamma_{i, 0}^{-}\right) n_{i}^{-} \\
& -\left(\beta_{i,-}^{-}+\beta_{i, 0}^{-}\right) n_{i}^{-}+\left(\gamma_{i+1,-}^{-} n_{i+1}^{-}+\gamma_{i+1,-}^{0} n_{i+1}^{0}\right)
\end{aligned}
$$

(negative, $i \geq 2$ )

where $n_{i}$ is the number concentration of embryos with $i$ sulfuric acid molecules, and $j_{\max }$ is the maximum embryo size tracked in the model. $\beta_{i, 0}, \beta_{i,+}$, and $\beta_{i,-}$ are condensational growth rate constants for embryos with $i$ sulfuric 
acid molecules to form neutral, positively charged, and negatively charged embryos one size larger (i.e, $i+1$ sulfuric acid molecules). Similarly, $\gamma_{i, 0}, \gamma_{i,+}$, and $\gamma_{i,-}$ are evaporation rate constants for embryos with $i$ sulfuric acid molecules to produce neutral, positively charged, and negatively charged embryos one size smaller (i.e, $i$-1 sulfuric acid molecules). The superscripts " 0 ", "+", and "-" in the concentration and rate constant terms refer to neutral, positively charged, and negatively charged embryos, and $\delta_{i}$ is a constant with a value of 0.5 when $i=2$ and a value of 1.0 otherwise.

Coagulation of different liquid embryos is described using the coagulation kernels in the IMN theory (Yu, 2006b). For liquid particles that are larger than $j_{\max }$, we use sectional bin approach (Jacobson and Turco, 1995) and Brownian coagulation kernels (Fuchs, 1989). In our model, we allow coagulation interactions between all liquid droplets except those between two positively charged or two negatively charged droplets.

Sulfur-induced activation is suggested to be an efficient pathway to increase the ability of exhaust soot emitted at altitude to host heterogeneous chemical reactions and to trigger the formation of contrail ice particles (Kärcher, 1998b). Activation and condensational growth of liquid coatings on soot is treated the same way as Kärcher (1998a) and our previous study (Wong et al., 2008). Activation is described as adsorption of $\mathrm{H}_{2} \mathrm{SO}_{4}, \mathrm{SO}_{3}$, or $\mathrm{H}_{2} \mathrm{SO}_{4}-\mathrm{H}_{2} \mathrm{O}$ embryos on soot particle surfaces. For example, the amount of sulfate mass $(\mathrm{m})$ adsorbed on soot particles in the $i$-th bin can be expressed as:

$$
\frac{d m_{i}}{d t}=\frac{\pi}{4} \cdot \alpha \cdot \bar{c} \cdot d_{p, i}^{2} \cdot\left(1-\theta_{i}\right) \cdot C_{a} \cdot M_{w, a}
$$

where $\alpha$ is the mass accommodation coefficient of $\mathrm{H}_{2} \mathrm{SO}_{4}$ on the uncovered fraction of soot surface, $\bar{c}$ is mean particle thermal speed, $d_{p, i}$ is soot particle diameter, $\theta$ is the covered (activated) fraction of the soot surface, $C_{a}$ is $\mathrm{H}_{2} \mathrm{SO}_{4}$ concentration, and $M_{w, a}$ is $\mathrm{H}_{2} \mathrm{SO}_{4}$ molecular weight. The resulting change in activation fraction on soot surface by $\mathrm{H}_{2} \mathrm{SO}_{4}$ is described as:

$\frac{d \theta_{i}}{d t}=\frac{1}{4} \cdot \alpha \cdot \bar{c} \cdot \frac{N_{0}}{\sigma_{0}} \cdot\left(1-\theta_{i}\right) \cdot C_{a}$

where $N_{0}$ is Avogadro's number, $\sigma_{0}$ is average number of sites (molecules) per unit area of soot surface set at $5 \times 10^{18} \mathrm{~m}^{-2}$. In our model, we allow $\mathrm{H}_{2} \mathrm{SO}_{4}$ and $\mathrm{SO}_{3}$ to condense on soot surface. We also consider the coagulation of $\mathrm{H}_{2} \mathrm{SO}_{4}-\mathrm{H}_{2} \mathrm{O}$ embryos and liquid droplets with coated soot particles. However, no coagulation between soot particles is allowed.

To simplify our calculations, the homogeneous $\mathrm{H}_{2} \mathrm{SO}_{4}$ $\mathrm{H}_{2} \mathrm{O}$ droplets produced in our simulations are not allowed to freeze. This is because these small homogeneous droplets are very acidic and their composition dependent freezing temperatures, based on the phase diagram reported by Gable et al. (1950), are lower than the ambient temperature of interest in this study. This treatment is also consistent with the slow homogeneous freezing rates calculated by the parameterized classical theory of homogeneous freezing (Tabazadeh et al., 1997). Previous microphysical calculations (Kärcher, 1998a; Kärcher et al., 1996; Pruppacher and Klett, 1997) suggest that heterogeneous freezing, rather than homogeneous freezing, is the main driving force to form contrail ice particles. Using the modified classical theory of heterogeneous freezing, these calculations show that liquid coated soot particles with a size of $20 \mathrm{~nm}$ and a contact angle of $50^{\circ}$ would induce heterogeneous freezing in a very short time scale of $10^{-2} \mathrm{~s}(\sim 2.5-5 \mathrm{~m}$ in distance) after $70 \mathrm{~m}$ downstream. These calculations, as well as our modeling results, also show that soot surface coverage by liquid coatings is generally less than $30 \%$ before freezing in a typical aircraft plume at cruise for typical fuel sulfur contents. Rate estimation for heterogeneous ice nucleation on soot cores remains uncertain (Kärcher et al., 1996) and only parametric studies are possible. For this reason, we assume coatings on soot particles only freeze heterogeneously as soon as plume temperature drops below their freezing temperatures, which are determined by their sulfate mass fraction based on the phase diagram reported by Gable et al. (1950). Although this approximation gives us an upper bound of size and number concentration of ice particles produced, we do find our representative modeling results, which will be discussed in the next section, consistent with available modeling results (Kärcher, 1998a; Kärcher and Yu, 2009) and measurement data (Schröder et al., 2000; Schumann, 2002).

Enhancement of nucleation rates by organic species has been shown in the laboratory (Zhang et al., 2004). Recent field campaigns measuring aircraft emissions at ground-level also demonstrate that this process may be important especially at low to mid power range where significantly more organic emissions are present in the gas and condensed phases (Knighton et al., 2007; Yelvington et al., 2007). However, knowledge of nucleation or particle growth enhanced by organic species is still limited, as are the species involved and the process by which the organic compounds contribute to the aerosol growth. Due to this reason, we do not explicitly consider the effects of organic species in these calculations. The entrainment of ambient particles is also neglected in this work because the concentration of ambient particles in the soot-rich regime is much smaller than the aircraft emitted particles in near-field aircraft plumes with a downstream distance smaller than $1000 \mathrm{~m}$. Although our model may not capture all the microphysical details, we believe that our modeling results will provide valuable information to understand the parametric effects of contrail ice particle formation from aircraft emissions at cruise. The simulation results are also a good source for interpreting current measurement data. 
(a)

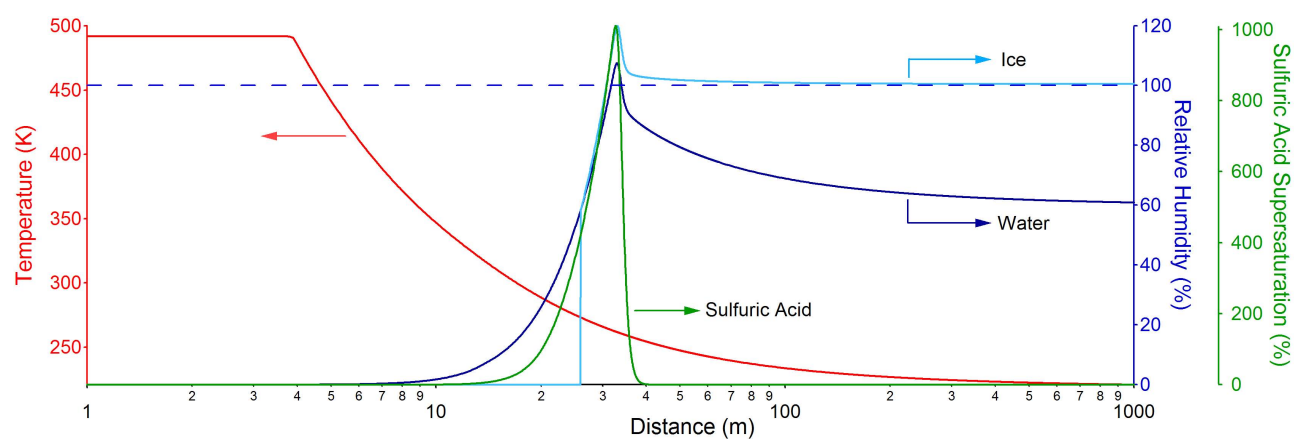

(b)

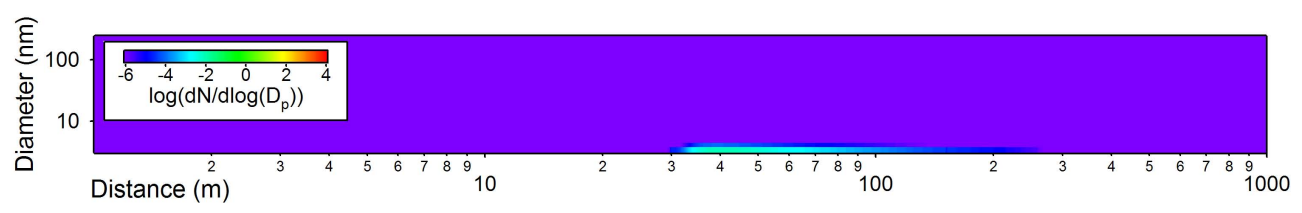

(c)

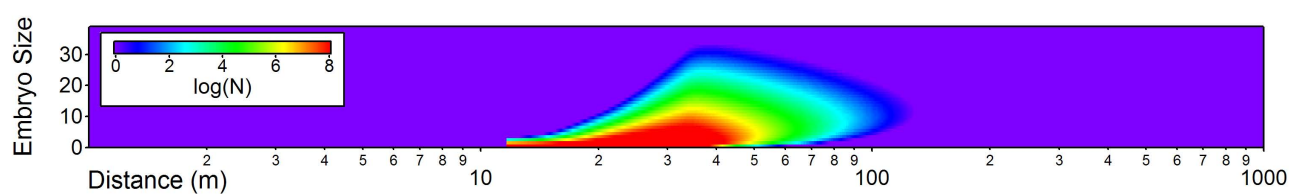

(d)

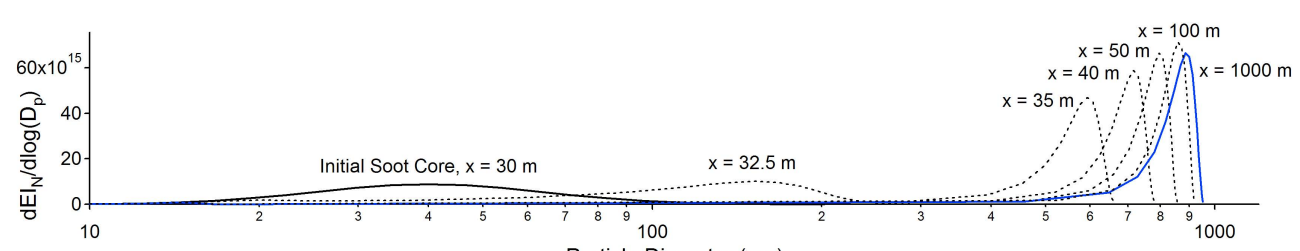

Particle Diameter $(\mathrm{nm})$

(e)

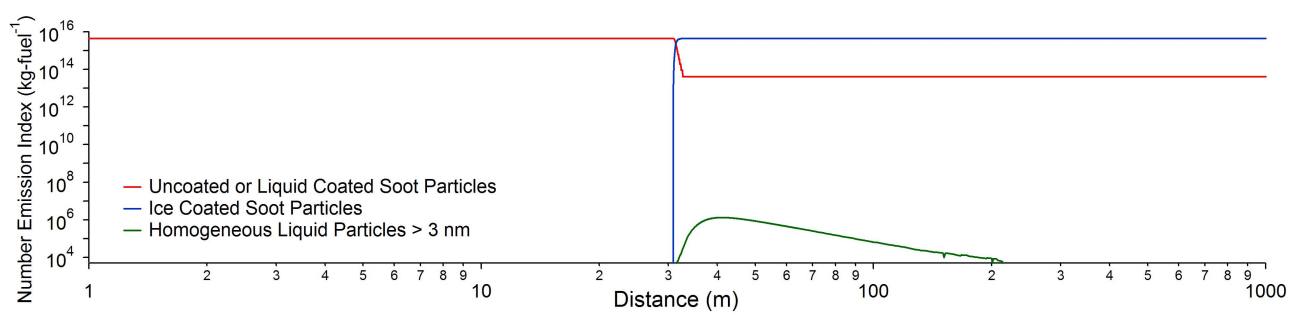

Fig. 1. Representative simulation results following the plume centerline trajectory up to $1000 \mathrm{~m}$ downstream: (a) trajectories of plume temperature, and ice, water, and acid supersaturation as a function of downstream distance; (b) concentration and size evolution of volatile $\mathrm{H}_{2} \mathrm{SO}_{4}-\mathrm{H}_{2} \mathrm{O}$ droplets; (c) concentration and size evolution of volatile $\mathrm{H}_{2} \mathrm{SO}_{4}-\mathrm{H}_{2} \mathrm{O}$ embryos smaller than 40 acid molecules; (d) size evolution of ice coated soot particles; (e) number emission index of different types of particles as a function of distance.

\section{Results and discussions}

\subsection{Representative modeling results and model validation}

We have performed detailed microphysical parcel simulations for PW4056 engines equipped on some Boeing 767 aircraft, which have a wingspan of $47.5 \mathrm{~m}$. The parameters used for these simulations are listed in Table 1, which describes the ambient conditions and the engine operating parameters we used for a cruising altitude of $35000 \mathrm{ft}$. Effects of dilution history, ion-mediated nucleation, ambient relative humidity, fuel sulfur contents, and initial soot emissions are investigated and discussed in this work.
Figure 1 shows a set of representative results from a microphysical parcel simulation with an initial soot particle concentration of $1 \times 10^{7} \mathrm{cc}^{-1}$ (which corresponds to a number emission index, $\mathrm{EI}_{N}$, of $\left.\sim 4.6 \times 10^{15}(\mathrm{~kg} \text {-fuel })^{-1}\right)$, an initial soot geometric mean diameter (GMD) of $40 \mathrm{~nm}$, a GMD standard deviation of 1.6, a fuel sulfur content level of $400 \mathrm{ppm}$ by weight, and an ambient relative humidity with respect to ice of $100 \%$. In our model, the growth of homogeneous $\mathrm{H}_{2} \mathrm{SO}_{4}-\mathrm{H}_{2} \mathrm{O}$ particles is tracked individually if they contain no more than 40 sulfuric acid molecules (Fig. 1c). For larger homogeneous particles, we distribute them lognormally into 30 bins (Jacobson and Turco, 1995) from about 3 to $250 \mathrm{~nm}$ in diameter while they are formed (Fig. 1b). For 
Table 1. Parameters used for the microphysical parcel simulations in this work.

\begin{tabular}{ll}
\hline Cruise Altitude & $35000 \mathrm{ft}$ \\
Ambient Temperature & $218.80 \mathrm{~K}$ \\
Ambient Pressure & $23.84 \mathrm{kPa}$ \\
Ambient Air Density & $0.38 \mathrm{~kg} / \mathrm{m}^{3}$ \\
Cruise Speed & $236.79 \mathrm{~m} / \mathrm{s}(0.8 \mathrm{M})$ \\
Net Thrust & $42.18 \mathrm{kN}$ \\
Core Mass Flow Rate & $52.72 \mathrm{~kg} / \mathrm{s}$ \\
Bypass Mass Flow Rate & $247.03 \mathrm{~kg} / \mathrm{s}$ \\
Fuel Mass Flow Rate & $0.69 \mathrm{~kg} / \mathrm{s}$ \\
Bypass Ratio & 4.69 \\
Core Total Temperature at Engine Exit & $590.23 \mathrm{~K}$ \\
Bypass Total Temperature at Engine Exit & $288.36 \mathrm{~K}$ \\
Core Flow Velocity at Engine Exit & $444.60 \mathrm{~m} / \mathrm{s}$ \\
Bypass Flow Velocity at Engine Exit & $310.76 \mathrm{~m} / \mathrm{s}$ \\
\hline
\end{tabular}

soot particles (Fig. 1d), we use 30 log-normally distributed bins to represent their initial particle size distributions at the engine-exit plane and let them evolve separately afterwards. As illustrated in the figure, the nucleation of homogeneous $\mathrm{H}_{2} \mathrm{SO}_{4}-\mathrm{H}_{2} \mathrm{O}$ particles takes place as sulfuric acid and water supersaturation is highest about $30 \mathrm{~m}$ downstream. It is known that the acidity of homogeneous $\mathrm{H}_{2} \mathrm{SO}_{4}-\mathrm{H}_{2} \mathrm{O}$ particles increases with decreasing particle size (Yu, 2005), and particles that are more acidic have lower freezing temperatures (Gable et al., 1950). As a result, small volatile particles formed from homogeneous nucleation are too acidic to freeze when water supersaturation is above $100 \%$. After water supersaturation drops below $100 \%$, additional water condensation on liquid particle surface to have significant particle growth becomes thermodynamically unfavorable. In contrast, coatings on soot particles begin to freeze after about $30 \mathrm{~m}$ downstream (Fig. 1e), and ice coated soot particles grow to a size of around $1 \mu \mathrm{m}$ at $1000 \mathrm{~m}$ downstream (Fig. 1d). The growth of these particles is the most rapid in the first $100 \mathrm{~m}$, especially in between $30-50 \mathrm{~m}$, where the particle growth is driven mostly by the supersaturation of water vapor emitted from the engines. The ice particle growth after $100 \mathrm{~m}$ is more moderate compared to the first $100 \mathrm{~m}$ and is driven by the modest supersaturation of water with respect to ice affected by ambient relative humidity levels. Our simulation results suggest that ice particles are mainly formed by water condensation on emitted soot particles under this condition, which is consistent with the modeling results in the soot-rich regime $\left(\mathrm{EI}_{N}>1 \times 10^{15}(\mathrm{~kg} \text {-fuel })^{-1}\right)$ by Kärcher and $\mathrm{Yu}$ (2009). Our results are also agreeable with the laboratory findings in freezing experiments of soot particles immersed in water droplets that heterogeneous freezing on soot surfaces is more favorable than homogeneous freezing of unseeded water droplets (Popovicheva et al., 2008). Note that the ice particle size distributions predicted from our model become narrower at later plume ages (Fig. 1e). As will be

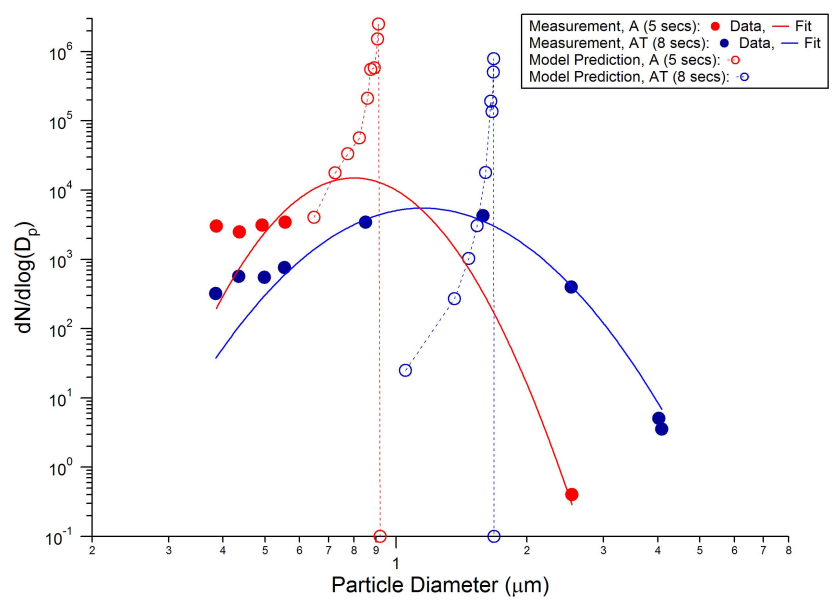

Fig. 2. Comparison of model predicted ice particle size distributions with near-field measurement results reported in the paper by Schröder et al. (2000).

discussed in the next section, our model approaches dilution using the profiles based on locally averaged plume properties along the trajectories. As a result, the effects of turbulence on the evolution of contrail ice particles are not considered. Therefore, the variances of the contrail ice particle size distributions predicted from our model are likely underestimated, especially at later plume ages.

To validate our microphysical model, we have selected data from two sets of near-field measurements reported in the paper by Schröder et al. (2000) for comparison: the Attas aircraft $8 \mathrm{~s}$ after emissions (AT) and an Airbus A-310 jet $5 \mathrm{~s}$ after emissions (A). The ambient conditions of these cases are listed in Table 2 of their paper, and the model predicted particle size distributions using these conditions are compared with the measurement data in Fig. 2. As shown in the figure, our model is able to predict the mean size of the contrail ice particles for the cases studied. However, the model predicted much narrower particle size distributions than the measurements. As mentioned briefly earlier and as will be discussed in detail in the next section, our model only tracks ice particle formation using the dilution profile based on locally averaged plume properties along the trajectories. Ambient mixing in the radial direction and entrainments due to vortex turbulence are not considered. As a result, we may not capture the inhomogeneity in aircraft plumes, which may explain the narrower particle size distributions predicted from our model.

\subsection{Effects of dilution history}

Since plume dilution in our model is based on a simple equation (Schumann et al., 1998) that was determined largely from measured plume properties for a plume age greater than $0.2 \mathrm{~s}(\sim 50 \mathrm{~m}$ downstream), the dilution history within the first wing span downstream of an engine may not be accurately captured. To study the sensitivity of contrail ice 
(a)

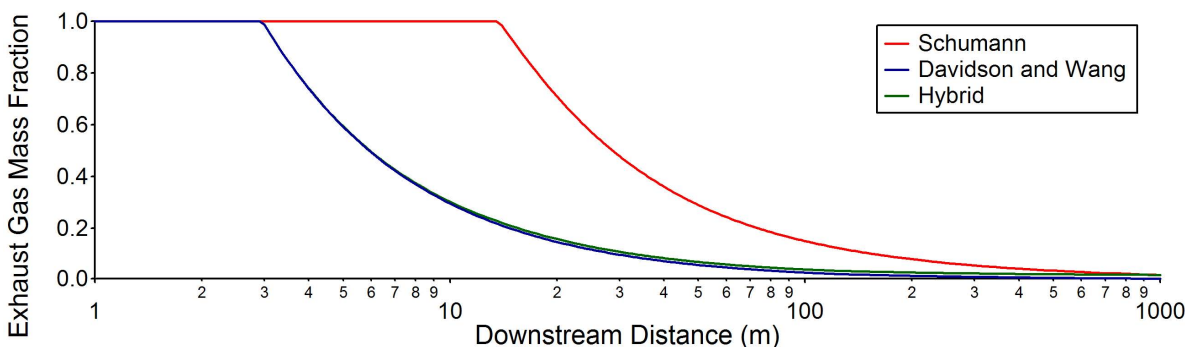

(b)

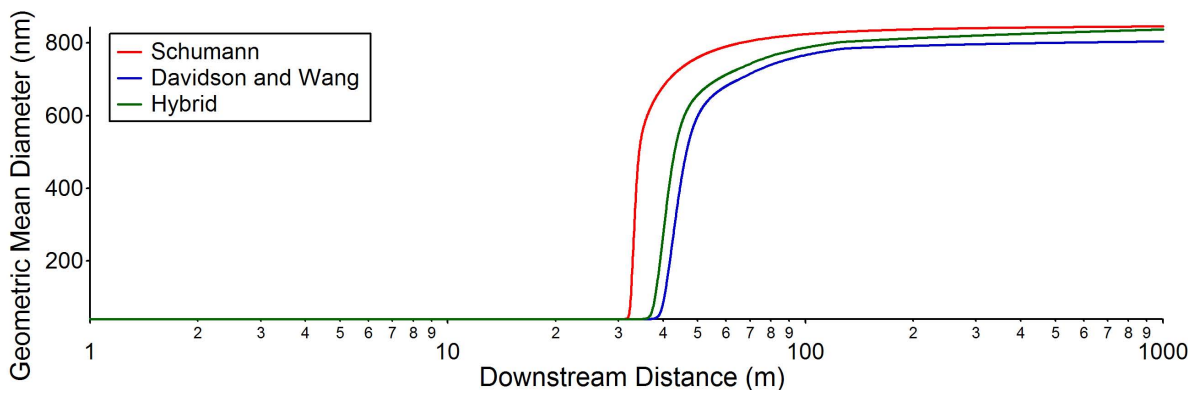

(c)

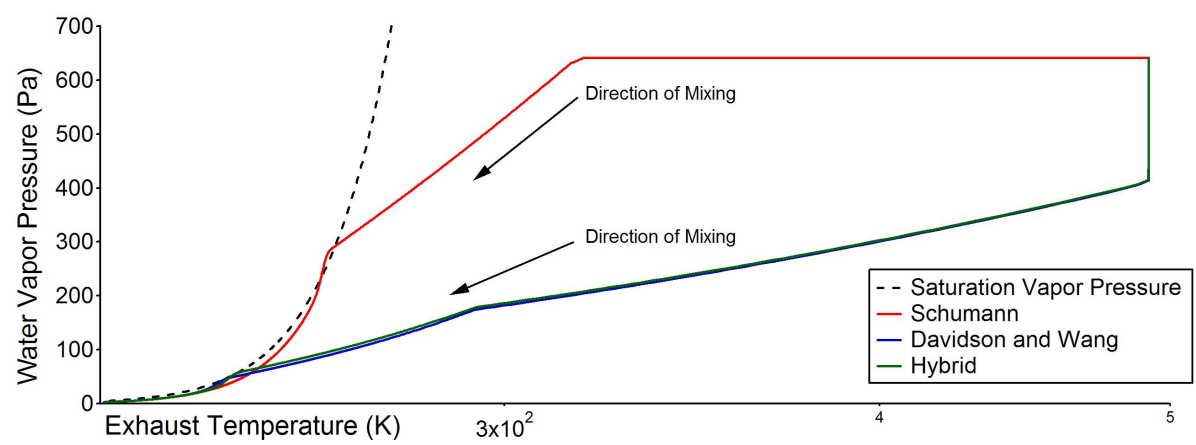

Fig. 3. (a) Exhaust mass fraction determined from the Schumann equation, the Davidson and Wang algorithm, and the hybrid of the two; (b) the predicted values of geometric mean diameter of the ice coated soot particles using different dilution profiles; (c) the water vapor pressure following different mixing trajectories and its relevance to saturation vapor pressure. Because both the Schumann equation and the Davidson and Wang algorithm are set up to match plume properties more than one wingspan downstream, they do not capture the behavior of the potential core region $(<15 \mathrm{~m}$ downstream) well. This results in the bended lines in the high temperature $(>300 \mathrm{~K})$, potential core region.

particle formation to plume dilution history immediately after engine-exit plane, we employed a semi-empirical, selfsimilar approach developed by Davidson and Wang (2002) in addition to the Schumann equation to estimate exhaust dilution. The Davidson and Wang algorithm describes the behavior of a nonbuoyant discharge in a coflowing ambient fluid, and was found to be able to capture the dilution behavior of near-field aircraft plumes at ground-level at $30 \mathrm{~m}$ downstream very well (Wong et al., 2008). As shown in Fig. 3a, the exhaust dilution profile estimated from the Davidson and Wang algorithm under the same ambient and engine operating conditions is faster than that is determined from the Schumann equation. The final exhaust mass fraction at 1000 $\mathrm{m}$ downstream is also lower $(\sim 0.5 \%$ compared to $\sim 2 \%)$. To eliminate the effects of different dilution level at the end of $1000 \mathrm{~m}$, we also introduced a hybrid profile of the two, which approximates the fast dilution of the Davidson and Wang profile in the first $500 \mathrm{~m}$ but approaches the final dilution level of the Schumann profile at the end of the $1000 \mathrm{~m}$.
The predicted values of geometric mean diameter of the ice coated soot particles using different dilution profiles are shown in Fig. 3b. Although dilution is faster (and thus plume temperature also drops faster) for the Davidson and Wang profile, the rapid particle growth starts earlier when the Schumann profile is used. This is because higher water vapor concentration in the Schumann profile enables the exhaust to reach water vapor supersaturation sooner at a warmer temperature, as illustrated in Fig. 3c. The final particle size is slightly smaller when the Davidson and Wang profile is used. This is because the dilution level at $1000 \mathrm{~m}$ downstream is larger in this case and there is less available water vapor for condensation. On the other hand, the final particle size for the hybrid profile approaches the prediction for the Schumann equation, suggesting that differences in the dilution trajectories in the first $500 \mathrm{~m}$ only affects the onset of particle growth, but final particle size is determined by final dilution levels. This is consistent with the assumption that contrail ice particle formation is a thermodynamically controlled process. 
(a)

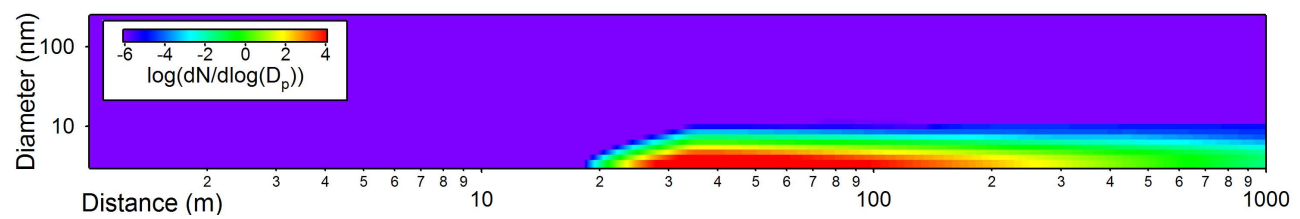

(b)
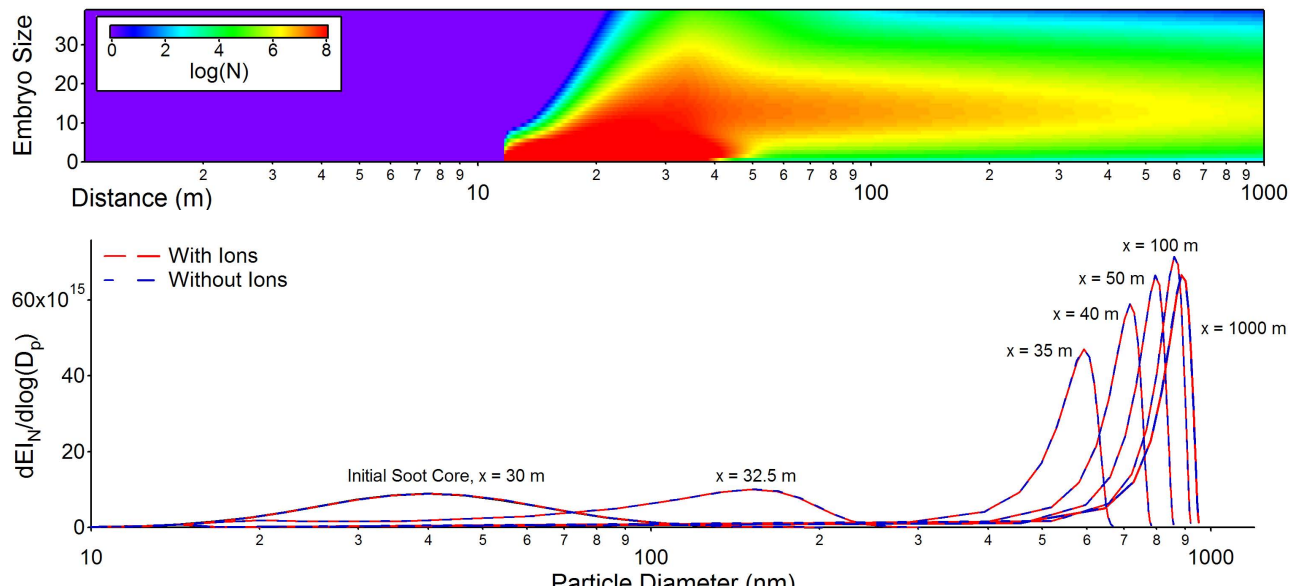

(c)

Particle Diameter $(\mathrm{nm})$

Fig. 4. Simulation results for ion-mediated homogeneous $\mathrm{H}_{2} \mathrm{SO}_{4}-\mathrm{H}_{2} \mathrm{O}$ nucleation under the same condition as Fig. 1: (a) concentration and size evolution of volatile $\mathrm{H}_{2} \mathrm{SO}_{4}-\mathrm{H}_{2} \mathrm{O}$ droplets; (b) concentration and size evolution of volatile $\mathrm{H}_{2} \mathrm{SO}_{4}-\mathrm{H}_{2} \mathrm{O}$ embryos smaller than 40 acid molecules; (c) ice coated soot particle size distributions as a function of downstream distance with or without ion-mediated nucleation.

Since our microphysical model only tracks particle evolution using the dilution profiles based on locally averaged plume properties along the trajectories, treatments of ambient air entrainment, turbulent mixing, and vortex interactions are extremely simplified. As a result, our modeling results may not capture the inhomogeneity of plume mixing in the radial directions. Although we anticipate the impact of mixing is smaller in the near-field $(<5 \mathrm{~s})$, this simplification of mixing treatment still may contribute to uncertainties of our model predictions. As mentioned in the previous section, one possible uncertainty may be the predicted variances (width) of the ice particle size distributions, since we may not capture all the particles experiencing different dilution histories. Further microphysical calculations using selected dilution trajectories from high-fidelity calculations, such as large eddy simulations, are necessary to quantify the effect of mixing profiles on contrail ice particle formation.

\subsection{Effects of ion-mediated nucleation}

The effects of ion-mediated nucleation have been studied extensively in the literature. It is believed that ions present in aircraft emissions at cruise have great impacts on homogeneous nucleation and formation on volatile sulfuric acidwater aerosols. However, their contribution to the formation of contrail ice particles is still uncertain. Here, we investigated the effects of ion-mediated nucleation on the formation of ice coated soot particles, as shown in Fig. 4. The ion-mediated nucleation model developed by Yu (2006b) was incorporated, and the same conditions used in Fig. 1 were chosen for Fig. 4. The initial ion concentration was assumed to come from ionization of $1 \%$ of the initial sulfuric acid concentration $\left(\sim 7.5 \times 10^{17}(\mathrm{~kg} \text {-fuel })^{-1}\right.$ for both positive and negative ions). As shown in the figure, the presence of chemi-ions does speed up the nucleation rates of homogeneous $\mathrm{H}_{2} \mathrm{SO}_{4}-\mathrm{H}_{2} \mathrm{O}$ particles, as evidenced by significant enhancement of embryo and droplet size and concentration (Fig. 4a and b). However, freezing of these larger liquid $\mathrm{H}_{2} \mathrm{SO}_{4}-\mathrm{H}_{2} \mathrm{O}$ particles formed from ion-mediated nucleation are still unfavorable such that their contribution to ice particle growth is limited. As a result, the growth of ice coated soot particles is not affected, as shown in Fig. 4c, and no significant increase of the ice particle size was observed with the addition of chemi-ions. Our modeling results suggest that the presence of chemi-ions in the soot-rich regime does not significantly contribute to the formation of additional ice nuclei to alter ice particle growth.

\subsection{Effects of ambient relative humidity and fuel sulfur contents}

Figure 5 shows the effects of ambient relative humidity with respect to ice (RHI) on ice coated soot particle size distributions. Four different levels of ambient RHI were studied in this work: $110 \%, 100 \%, 90 \%$, and $80 \%$. As shown in the figure, the growth of ice coated soot particles is most rapid in between 30-50 $\mathrm{m}$ downstream regardless ambient RHI levels. In this region, the effect of ambient RHI is negligible 


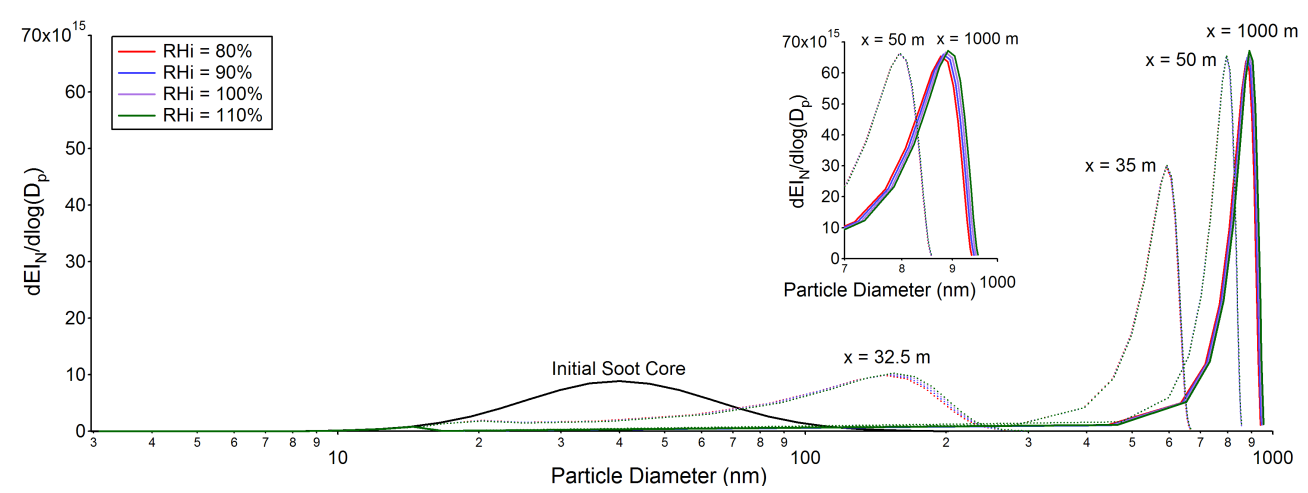

Fig. 5. Effects of ambient relative humidity with respect to ice (RHI) on ice particle size distributions at downstream distances of $32.5 \mathrm{~m}$, $35 \mathrm{~m}, 50 \mathrm{~m}$, and $1000 \mathrm{~m}$.

(a)

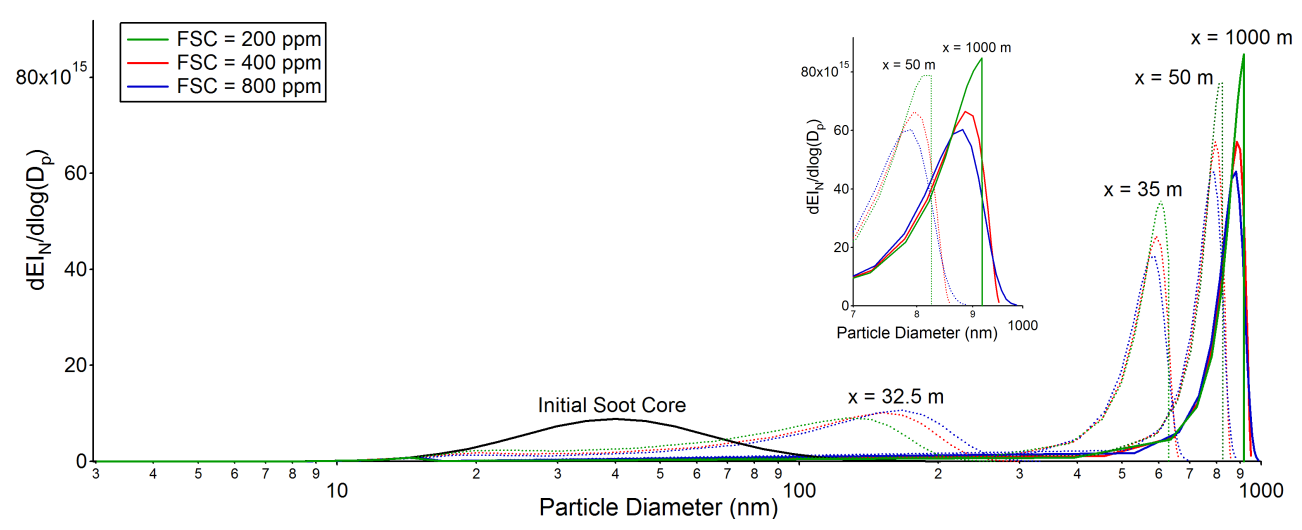

(b)

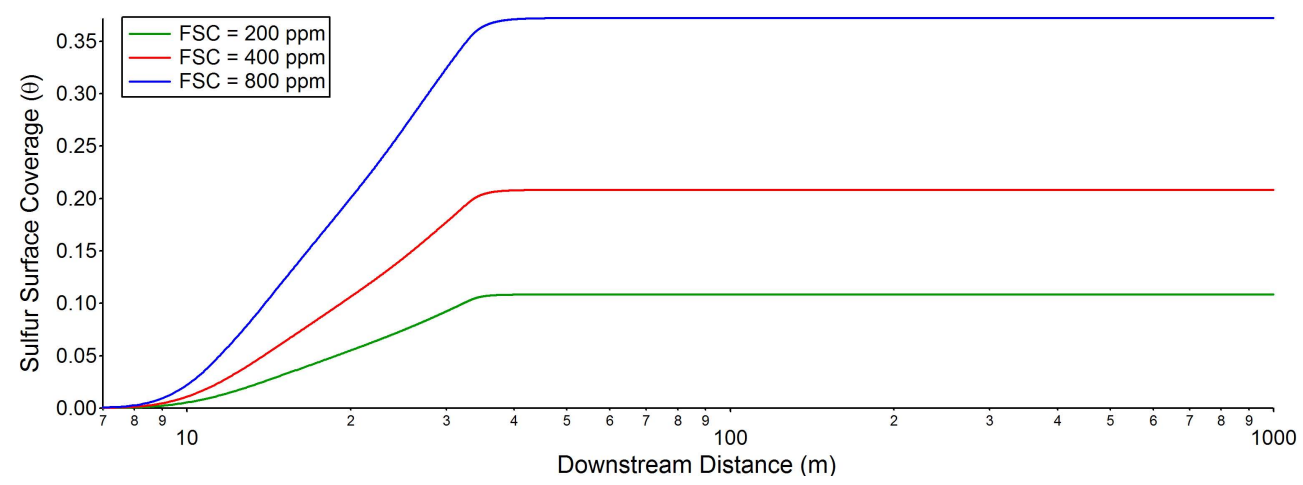

Fig. 6. Effects of fuel sulfur content (FSC) on: (a) ice particle size distributions at downstream distances of $32.5 \mathrm{~m}, 35 \mathrm{~m}, 50 \mathrm{~m}$, and $1000 \mathrm{~m}$; (b) sulfur activated fraction on soot surface.

because the particle growth is driven by water vapor emitted from aircraft engines. At $1000 \mathrm{~m}$ downstream, the ice coated soot particles under higher ambient RHI become slightly larger than those under lower ambient RHI. However, this difference is still quite small because the difference in ice supersaturation in the exhaust plume due to ambient is within $1 \%$ for such a short plume age $(\sim 4 \mathrm{~s})$. This further confirms that ice particle growth in the first $1000 \mathrm{~m}$ is driven by emitted water vapor condensation whereas ice particle growth afterwards is driven by ambient relative humidity.
Figure 6a shows the effects of fuel sulfur content (FSC) on particle size distributions of ice coated particles as a function of downstream distance. The same conditions in Fig. 1 were modeled, and two additional fuel sulfur levels, $200 \mathrm{ppm}$ and $800 \mathrm{ppm}$ by weight, were studied. Our calculation results show that the growth of ice coated soot particles is initially slower when fuel sulfur is lower at a downstream distance of around $32.5 \mathrm{~m}$. This is because lower fuel sulfur levels give lower initial $\mathrm{SO}_{3}$ and $\mathrm{H}_{2} \mathrm{SO}_{4}$ concentrations. As a result, a smaller fraction of the soot surface is activated by $\mathrm{SO}_{3}$ and 
(a)

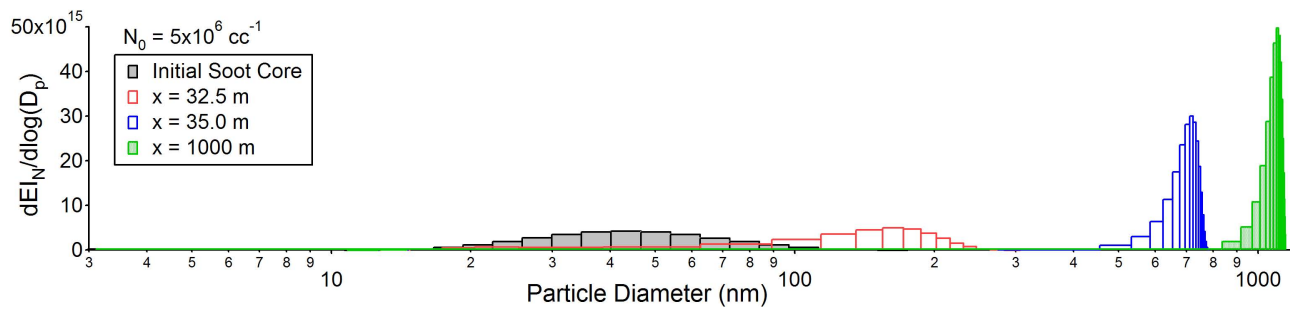

(b)

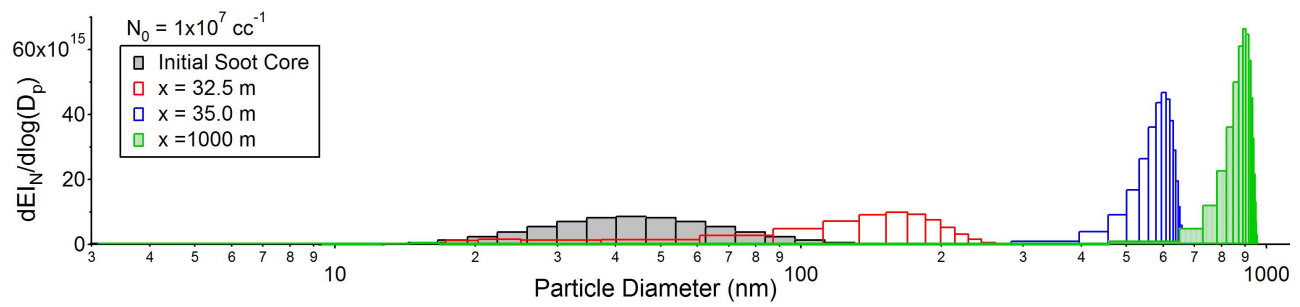

(c)

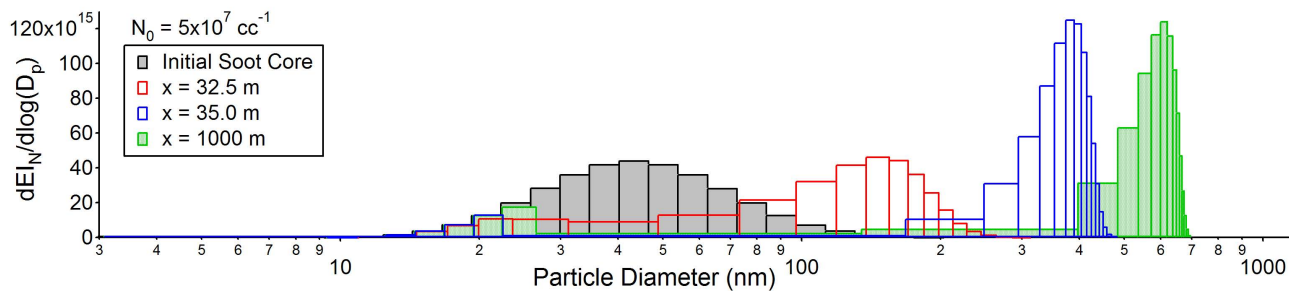

Fig. 7. Effects of initial soot core number concentration $\left(N_{0}\right)$ on size distributions of ice coated soot particles as a function of downstream distance $(x)$ when $N_{0}$ is: (a) $5 \times 10^{6} \mathrm{cc}^{-1}\left(\mathrm{EI}_{N} \sim 2.3 \times 10^{15}(\mathrm{~kg} \text {-fuel) })^{-1}\right)$; (b) $1 \times 10^{7} \mathrm{cc}^{-1}\left(\mathrm{EI}_{N} \sim 4.6 \times 10^{15}(\mathrm{~kg}-\mathrm{fuel})^{-1}\right)$; (c) $5 \times 10^{7} \mathrm{cc}-1$ $\left(\mathrm{EI}_{N} \sim 2.3 \times 10^{16}(\mathrm{~kg}-\text { fuel })^{-1}\right)$.

$\mathrm{H}_{2} \mathrm{SO}_{4}$ as illustrated in Fig. $6 \mathrm{~b}$ and the modeling results by Kärcher (1998a). This can be explained by the relationship between soot surface coverage $(\theta)$ and $\mathrm{H}_{2} \mathrm{SO}_{4}$ concentration $\left(C_{a}\right)$ in Eq. (6). Smaller activated area on soot surface effectively reduces water condensation rate on soot surface when the particles are small. When particles grow to a size that is much larger than the cores, however, the fraction of the activated soot surface becomes relatively unimportant because of much larger available ice surface area. In this case, the growth of ice coated soot particles is faster when fuel sulfur is lower, since binary homogeneous nucleation is not depleting water as effectively without enough $\mathrm{SO}_{3}$ and $\mathrm{H}_{2} \mathrm{SO}_{4}$ in the gas phase, resulting in higher water vapor concentration (and hence higher water supersaturation). This difference, however, is very small between FSCs of $200 \mathrm{ppm}$ and 800 ppm (Fig. 6a), since our model predicts that only slightly larger particles are formed for a fuel sulfur level of $200 \mathrm{ppm}$ at a downstream distance of $1000 \mathrm{~m}$. Our modeling results are consistent with experimental findings (Schumann et al., 2002) where no significant effect of fuel sulfur content on contrail formation was observed.

\subsection{Effects of soot emissions}

Studies on the effects of soot emissions on contrail ice particle properties are very limited in the literature. To our knowledge, the recent paper by Kärcher and Yu (2009) is the only modeling work that attempts to perform systematic studies on the roles of soot emissions in the formation and evolution of young contrails. It is suggested in their work that in the soot-rich regime $\left(\mathrm{EI}_{N}>1 \times 10^{15}(\mathrm{~kg} \text {-fuel })^{-1}\right)$ ice particles mainly form by freezing of water around soot cores, whereas in the soot-poor regime $\left(\mathrm{EI}_{N}<1 \times 10^{13}(\mathrm{~kg} \text {-fuel })^{-1}\right)$ ice particles mainly originate from liquid particles without soot cores. In this paper, we performed a similar parametric study to investigate the effects of initial number concentration and particle size distribution of soot emissions. We focus our work on the soot-rich regime, since it corresponds to the soot emissions from existing aircraft technology.

Figure 7 shows the effects of initial number concentration of soot particles on ice particle size distributions in the aircraft exhaust up to $1000 \mathrm{~m}$ downstream. Three different initial number loadings of soot particles were studied, and our simulation results show that size of ice coated soot particles at $1000 \mathrm{~m}$ downstream decreases with increasing initial soot concentration. This is because more soot particles are competing for water vapor and a smaller amount of water is condensed on each soot particle when initial soot concentration is higher. Note that when initial soot concentration is $5 \times 10^{7} \mathrm{cc}^{-1}$ (Fig. 7c), a bimodal particle size distribution is predicted from our calculation after $35 \mathrm{~m}$ downstream. The smaller mode of this particle size distribution represents those liquid coated soot particles. Because of 
(a)

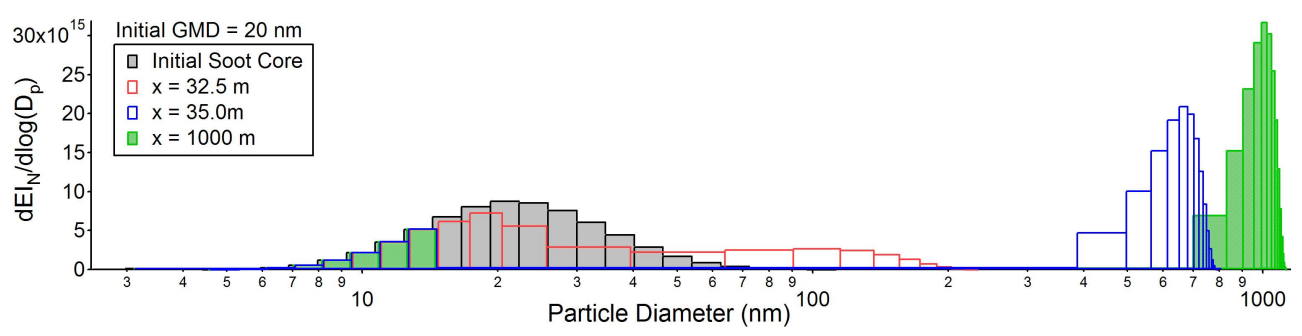

(b)

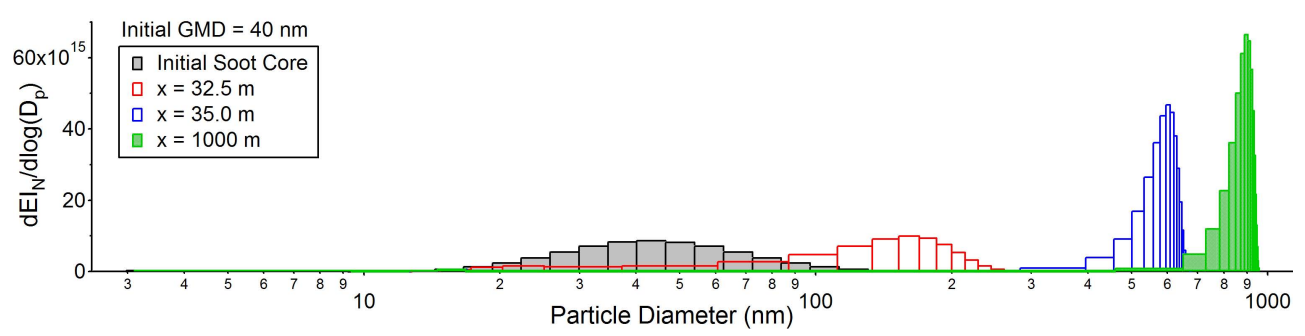

(c)

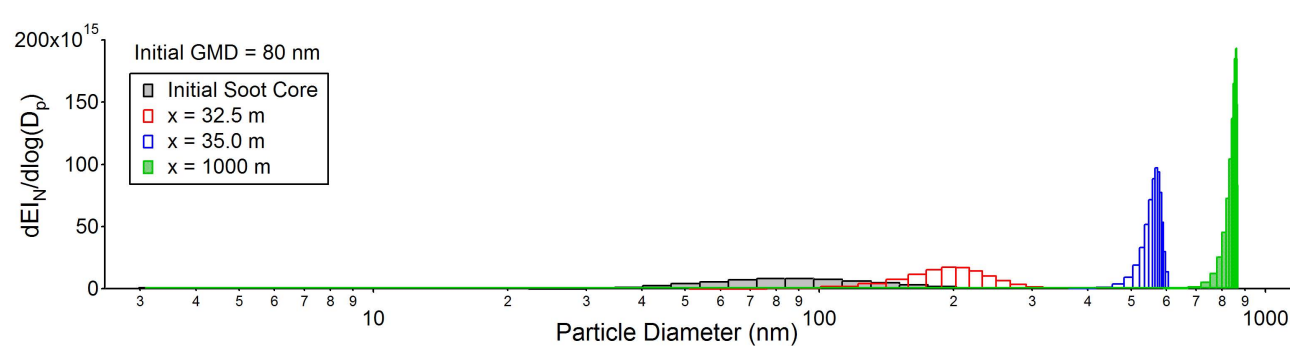

Fig. 8. Effects of initial soot core size on size distributions of ice coated soot particles as a function of downstream distance $(x)$ when geometric mean diameter (GMD) of initial particle size distribution of soot cores is: (a) $20 \mathrm{~nm}$; (b) $40 \mathrm{~nm}$; (c) $80 \mathrm{~nm}$.

the Kelvin effect and the smaller available surface area, the amount of water condensation on these liquid soot particles is smaller, resulting in more acidic coatings on them. Similar to homogeneous $\mathrm{H}_{2} \mathrm{SO}_{4}-\mathrm{H}_{2} \mathrm{O}$ particles formed from nucleation, these liquid particles are too acidic to freeze when water supersaturation is above $100 \%$. After water supersaturation drops below $100 \%$ (even though RHI is above $100 \%$ ), water condensation on liquid particle surface becomes thermodynamically unfavorable to grow into larger size. This prediction is consistent with the experimental findings by Popovicheva et al. (2008), where they suggested that hydrophilic coverage (e.g. sulfuric acid) on the hydrophobic soot surface higher than a threshold value could inhibit ice nucleation due to effective dissolution of water in the soluble surface coverage, reducing the likelihood of freezing of the solution.

Figure 8 shows the effects of initial soot particle size on the growth of ice coated soot particles in the aircraft exhaust up to $1000 \mathrm{~m}$ downstream. Three different particle size distributions of soot cores were initialized for calculations, and our simulation results show that smaller soot cores result in more liquid particles and fewer but larger ice particles. This is because liquid particles in the smaller mode of the bimodal particle size distribution are too acidic to freeze, and fewer soot particles in the large mode can serve as ice nuclei to compete for water vapor condensation. The resulting particle size distribution of ice coated soot particles is also broader for smaller soot cores since the split between the two modes are more marked.

Our above simulation results are agreeable with the modeling results by Kärcher et al. (1996), where they observed that an initial ice nuclei number density of $10^{5} \mathrm{~cm}^{-3}$ would result in smaller maximum ice particle size but larger optical depth than an initial ice nuclei number density of $10^{3} \mathrm{~cm}^{-3}$. Our results are also generally consistent with the modeling results in the soot-rich regime by Kärcher and Yu (2009). The effects of initial soot number concentration and initial soot core size observed in our model suggest that sufficiently high soot core number concentration and sufficiently small soot core size that were not investigated in Kärcher and Yu (2009) may be able to suppress ice particle growth. To validate this assumption, we performed a microphysical parcel calculation initialized with a hypothetical soot core number concentration of $1 \times 10^{10} \mathrm{cc}^{-1}\left(\mathrm{EI}_{N}=4.6 \times 10^{18}(\mathrm{~kg} \text {-fuel })^{-1}\right)$ and a GMD of soot core size distribution of $5 \mathrm{~nm}$. The simulation results are shown in Fig. 9. In this case, no significant ice particle growth is predicted from the model because all the particles are too acidic to freeze and are "trapped" in the liquid phase, limiting significant particle growth. The results shown in Fig. 9 suggest that ice particle growth could be suppressed 


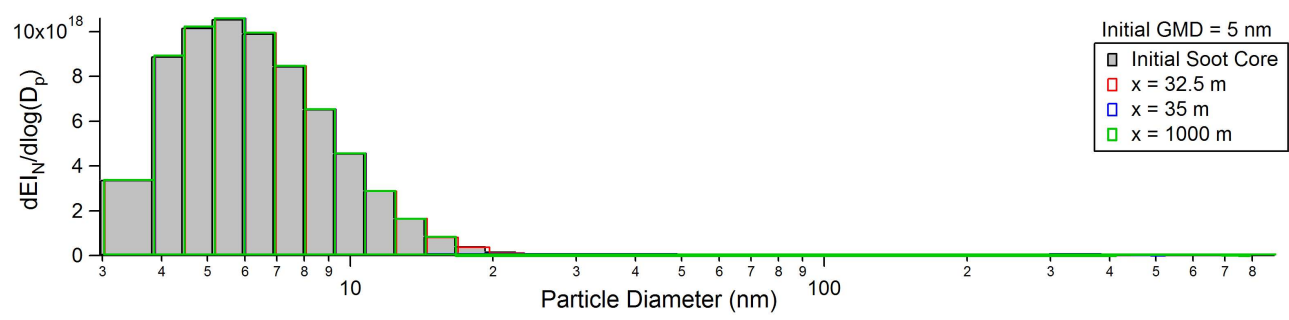

Fig. 9. Simulation results show no significant ice coated soot particle growth when initial soot core concentration is $1 \times 10^{10} \mathrm{cc}^{-1}$ and GMD of initial soot particle size distribution is $5 \mathrm{~nm}$.

by a high number concentration of sufficiently small contrail particle nuclei in aircraft emissions. Although existing engine technology does not produce such soot particles, our findings suggest that manipulation of the number and size of contrail particle nucleation sites may affect contrail properties and offers possibilities for potential mitigation. Further laboratory studies and field measurements are clearly needed to validate the above implication.

\section{Conclusions}

To gain systematic understanding of parametric effects of variables affecting contrail ice particle formation, we apply a microphysical parcel modeling approach to study microphysics of contrail ice particle formation in near-field aircraft plumes in the soot-rich regime (soot number emission index $>1 \times 10^{15}(\mathrm{~kg} \text {-fuel })^{-1}$ ) at cruise. Our calculations suggest that ice particles are mainly formed by water condensation on emitted soot particles in this regime. The growth of ice coated soot particles is more rapid in the $100 \mathrm{~m}$ downstream of an engine and is driven by water emissions. After $100 \mathrm{~m}$ downstream, the size of ice particles is mostly affected by ambient relative humidity with respect to ice but the effect of ambient relative humidity in the first $1000 \mathrm{~m}$ downstream remains insignificant. The presence of chemi-ions speeds up the nucleation rates of homogeneous $\mathrm{H}_{2} \mathrm{SO}_{4}-\mathrm{H}_{2} \mathrm{O}$ particles, but the growth of ice coated soot particles is not affected since these homogeneous particles are too acidic to freeze and do not serve as ice nuclei. The effect of fuel sulfur content is small, and our calculations show that only slightly larger particles at $1000 \mathrm{~m}$ downstream are formed for a lower fuel sulfur level at $200 \mathrm{ppm}$ by weight. The initial properties of soot emissions play the most critical role, and our calculations show that higher initial number concentrations of contrail particle nuclei result in smaller ice particles. In addition, a bimodal particle size distribution consisting of smaller liquid particles and larger ice particles is predicted when initial number concentration of soot cores is sufficiently high. Initializing with smaller soot particles also results in more liquid particles in the smaller mode of the bimodal distribution, suggesting that ice particle growth could be suppressed by a high number concentration of sufficiently small contrail particle nuclei in aircraft emissions. Further modeling and experimental studies are needed to verify if our findings can provide a possible approach for contrail mitigation.

Acknowledgements. The authors are grateful for financial support from the PARTNER Center of Excellence (jointly sponsored by the FAA, NASA and Transport Canada) via Stanford University (Contract No. 03-C-NE-SU, Subaward No. 15447830-32202A). We also thank Steven L. Baughcum and Mikhail Y. Danilin at Boeing and Sanjiva K. Lele at Stanford University for helpful discussions.

Edited by: B. Kärcher

\section{References}

Appleman, H.: The formation of exhaust condensation trails by jet aircraft, Bull. Am. Meteorol. Soc., 34, 14-20. 1953.

Brown, R. C., Miake-Lye, R. C., Anderson, M. R., Kolb, C. E., and Resch, T. J.: Aerosol dynamics in near-field aircraft plumes, J. Geophys. Res., 101, 22939-22953, 1996.

Davidson, M. J. and Wang, H. J.: Strongly advected jet in a coflow, J. Hydraulic Eng., 128, 742-752, 2002.

Fuchs, N. A.: The mechanics of aerosols, 2nd ed., Dover, New York, NY, 1989.

Gable, C. M., Betz, H. F., and Maron, S. H.: Phase equilibria of the system sulfur trioxide-water, J. Am. Chem. Soc., 72, 1445-1448, 1950.

Jacobson, M. Z. and Turco, R. P.: Simulating condensational growth, evaporation, and coagulation of aerosols using a combined moving and stationary size grid, Aerosol Sci. Technol., 22, 73-92, 1995.

Kärcher, B., Peter, T., Biermann, U. M., and Schumann, U.: The initial composition of jet condensation trails, J. Atmos. Sci., 53, 3066-3083, 1996.

Kärcher, B.: Physicochemistry of aircraft-generated liquid aerosols, soot, and ice particles: 1. Model description, J. Geophys. Res., 103, 17111-17128, 1998a.

Kärcher, B.: On the potential importance of sulphur-induced activation of soot particles in nascent jet aircraft exhaust plumes, Atmos. Res., 46, 293-305, 1998b.

Kärcher, B., Möhler, O., DeMott, P. J., Pechtl, S., and Yu, F.: Insights into the role of soot aerosols in cirrus cloud formation, Atmos. Chem. Phys., 7, 4203-4227, 2007, http://www.atmos-chem-phys.net/7/4203/2007/. 
Kärcher, B. and Yu, F.: Role of aircraft soot emissions in contrail formation, Geophys. Res. Lett., 36, L01804, doi:10.1029/2008GL036649, 2009.

Knighton, W. B., Rogers, T. M., Anderson, B. E., Herndon, S. C., Yelvington, P. E., and Miake-Lye, R. C.: Quantification of aircraft engine hydrocarbon emissions using proton transfer reaction mass spectrometry, J. Propul. Power, 23, 949-958, 2007.

Lee, D. S., Fahey, D. W., Forster, P. M., Newton, P. J., Wit, R. C. N., Lim, L. L., Owen, B., and Sausen, R.: Aviation and Global Climate Change in the 21st Century, Atmos. Environ., 43, 35203537, 2009.

Minnis, P., Ayers, J. K., Palikonda, R., and Phan, D.: Contrails, cirrus trends, and climate, J. Climate, 17, 1671-1685, 2004.

Mueller, M. A., Yetter, R. A., and Dryer, F. L.: Kinetic modeling of the $\mathrm{CO} / \mathrm{H}_{2} \mathrm{O} / \mathrm{O}_{2} / \mathrm{NO} / \mathrm{SO}_{2}$ system: Implications for high-pressure fall-off in the $\mathrm{SO}_{2}+\mathrm{O}(+\mathrm{M})=\mathrm{SO}_{3}(+\mathrm{M})$ reaction, Inter. J. Chem. Kinet., 32, 317-339, 2000.

Popovicheva, O., Kireeva, E., Persiantseva, N., Khokhlova, T., Shonija, N., Tishkova, V., and Demirdjian, B.: Effect of soot on immersion freezing of water and possible atmospheric implications, Atmos. Res., 90, 326-337, 2008.

Pruppacher, H. R. and Klett, J. D: Microphysics of clouds and precipitation, 2nd ed., Kluwer Academic Publishers, Dordrecht, The Netherlands, 1997.

Sausen R., Isaksen, I., Grewe, V., Hauglustaine, D., Lee, D. S., Myhre, G., Köhler, M. O., Pitari, G., Schumann, U., Stordal, F., and Zerefos, C.: Aviation radiative forcing in 2000: An update on IPCC (1999), Meteorol. Z., 14, 555-561, 2005.

Schmidt, E.: Die entstehung von eisnebel aus den auspuffgasen von flugmotoren, Schriften der Deutschen Akademie der Luftfahrtforschung, 44, 1-15, 1941.

Schröder, F., Kärcher, B., Duroure, C., Ström, J., Petzold, A., Gayet, J.-F., Strauss, B., Wendling, P., and Borrmann, S.: On the transition of contrails into cirrus clouds, J. Atmos. Sci., 57, 464-480, 2000.

Schumann, U., Schlager, H., Arnold, F., Baumann, R., Haschberger, P., and Klemm, O.: Dilution of aircraft exhaust plumes at cruise altitudes, Atmos. Environ., 32, 3097-3103, 1998.

Schumann, U., Schlager, H., Arnold, F., Ovarlez, J., Kelder, H., Hov, Ø., Hayman, G., Isaksen, I. S. A., Staehelin, J., and Whitefield, P. D.: Pollution from aircraft emissions in the North Atlantic flight corridor: Overview on the POLINAT projects, J. Geophys. Res., 105, 3605-3631, 2000.

Schumann, U., Arnold, F., Busen, R., Curtius, J., Kärcher, B., Kiendler, A., Petzold, A., Schlager, H., Schröder, F., and Wohlfrom, K.-H.: Influence of fuel sulfur on the composition of aircraft exhaust plumes: The experiments SULFUR 1-7, J. Geophys. Res., 107, AAC2-1-AAC2-27, doi:10.1029/2001JD000813, 2002.
Schumann, U.: Formation, properties and climate effects of contrails, Comptes Rendus Physique, 6, 549-565, 2005.

Shirgaonkar, A. A. and Lele, S. K.: Large eddy simulation of contrails: Effect of atmospheric properties, AIAA Paper 2006-1414, 44th AIAA Aerospace Sciences Meeting and Exhibit, Reno, Nevada, 2006.

Tabazadeh, A, Jensen, E. J., and Toon, O. B.: A model description for cirrus cloud nucleation from homogeneous freezing of sulfate aerosols, J. Geophys. Res., 102, 23845-23850, 1997.

Toon, O. B. and Miake-Lye, R. C.: Subsonic aircraft: Contrail and cloud effects special study (SUCCESS), Geophys. Res. Lett., 25, 1109-1112, 1998.

Yu, F. and Turco, R. P.: Contrail formation and impacts on aerosol properties in aircraft plumes: Effects of fuel sulfur content, Geophys. Res. Lett., 25, 313-316, 1998.

Yu, F.: Quasi-unary homogeneous nucleation of $\mathrm{H}_{2} \mathrm{SO}_{4}-\mathrm{H}_{2} \mathrm{O}$, J. Chem. Phys., 122, 074501/1-074501/8, doi:10.1063/1.1850472, 2005.

$\mathrm{Yu}, \mathrm{F}$.: Binary $\mathrm{H}_{2} \mathrm{SO}_{4}-\mathrm{H}_{2} \mathrm{O}$ homogeneous nucleation based on kinetic quasi-unary nucleation model: Look-up tables, J. Geophys. Res., 111, D04201/1-D04201/17, doi:10.1029/2005JD006358, 2006a.

Yu, F.: From molecular clusters to nanoparticles: Secondgeneration ion-mediated nucleation model, Atmos. Chem. Phys., 6, 5193-5211, 2006b,

http://www.atmos-chem-phys.net/6/5193/2006/.

$\mathrm{Yu}, \mathrm{F}$.: Improved quasi-unary nucleation model for binary $\mathrm{H}_{2} \mathrm{SO}_{4}-$ $\mathrm{H}_{2} \mathrm{O}$ homogeneous nucleation, J. Chem. Phys., 127, 054301/1054301/8, doi:10.1063/1.275217, 2007.

Wong, H.-W., Yelvington, P. E., Timko, M. T., Onasch, T. B., Miake-Lye, R. C., Zhang, J., and Waitz, I. A.: Microphysical modeling of ground-level aircraft-emitted aerosol formation: Roles of sulfur-containing species, J. Propul. Power, 24, 590602, 2008.

Wuebbles, D.: Workshop on the impacts of aviation on climate change: A report of findings and recommendations, Joint Planning and Development Office Environmental Integrated Product Team, REPORT No. PARTNER-COE-2006-004, Cambridge, MA, 2006.

Yelvington, P. E., Herndon, S. C., Wormhoudt, J. C., Jayne, J. T., Miake-Lye, R. C., Knighton, W. B., and Wey, C.: Chemical speciation of hydrocarbon emissions from a commercial aircraft engine, J. Propul. Power, 23, 912-918, 2007.

Zhang, R., Suh, I., Zhao, J., Zhang, D., Fortner, E. C., Tie, X., Molina, L. T., and Molina, M. J.: Atmospheric new particle formation enhanced by organic acids, Science, 304, 1487-1490, 2004. 